\title{
openheart Coronary risk stratification of patients with newly diagnosed heart failure
}

\author{
Rasmus Bo Hasselbalch (1) , ${ }^{1}$ Mia Pries-Heje, ${ }^{1}$ Thomas Engstrøm, ${ }^{2}$ \\ Andreas Sandø, ${ }^{1}$ Merete Heitmann, ${ }^{3}$ Frants Pedersen, ${ }^{2}$ Morten Schou, ${ }^{1}$ \\ Hans Mickley, ${ }^{4}$ Hanne Elming, ${ }^{5}$ Rolf Steffensen, ${ }^{6}$ Lars Koeber, ${ }^{2}$ \\ Kasper Karmark Iversen ${ }^{1}$
}

\begin{abstract}
- Additional material is published online only. To view, please visit the journal online (http://dx.doi.org/10.1136/ openhrt-2019-001074).
\end{abstract}

To cite: Hasselbalch RB, Pries-Heje M, Engstrøm T, et al. Coronary risk stratification of patients with newly diagnosed heart failure. Open Heart 2019;6:e001074. doi:10.1136/ openhrt-2019-001074

Received 23 April 2019 Revised 18 June 2019 Accepted 12 September 2019

Check for updates

(C) Author(s) (or their employer(s)) 2019. Re-use permitted under CC BY-NC. No commercial re-use. See rights and permissions. Published by BMJ.

${ }^{1}$ Department of Cardiology, Herlev og Gentofte Hospital, Herlev, Denmark

${ }^{2}$ Department of Cardiology, Copenhagen University Hospital, Copenhagen, Denmark ${ }^{3}$ Department of Cardiology, Bispebjerg University Hospital, Copenhagen, Denmark ${ }^{4}$ Department of Cardiology, Odense University Hospital, Odense, Denmark ${ }^{5}$ Department of Cardiology, Roskilde Sygehus, Roskilde, Denmark

${ }^{6}$ Department of Cardiology, Nordsjaellands Hospital, Hilleroed, Denmark

Correspondence to Dr Rasmus Bo Hasselbalch; rasmus.bo.hasselbalch@ regionh.dk

\section{ABSTRACT}

Objective Coronary artery disease (CAD) is frequent in patients with newly diagnosed heart failure (HF). Multislice CT (MSCT) is a non-invasive alternative to coronary angiography (CAG) suggested for patients with a low-tointermediate risk of CAD. No established definition of such patients exists. Our purpose was to develop a simple score to identify as large a group as possible with a suitable pretest risk of CAD.

Methods Retrospective study of patients in Denmark undergoing CAG due to newly diagnosed HF from 2010 to 2014. All Danish patients were registered in two databases according to geographical location. We used data from one registry and multiple logistic regression with backwards elimination to find predictors of $C A D$ and used the derived OR to develop a clinical risk score called the CT-HF score, which was subsequently validated in the other database. Results The main cohort consisted of 2171 patients and the validation cohort consisted of 2795 patients with $24 \%$ and $27 \%$ of patients having significant CAD, respectively. Among significant predictor, the strongest was extracardiac arteriopathy (OR 2.84). Other significant factors were male sex, smoking, hyperlipidaemia, diabetes mellitus, angina and age. A proposed cut-off of 9 points identified $61 \%$ of patients with a $15 \%$ risk of having $C A D$, resulting in an estimated savings of $15 \%$ of the cost and $21 \%$ of the radiation.

Conclusions A simple score based on clinical risk factors could identify HF patients with a low risk of CAD; these patients may have benefitted from MSCT as a gatekeeper for CAG.

\section{INTRODUCTION}

With the ageing population and improved survival after myocardial infarction, heart failure (HF) is an increasing public health concern. ${ }^{1}$ Coronary artery disease (CAD) is the largest contributor among men in the development of $\mathrm{HF}^{2}$ and maybe an aetiological factor in as many as $65 \%$ of all cases. $\mathrm{CAD}$ also represents a treatable, if not reversible, factor. ${ }^{3}$ However, new data suggest that testing for CAD among patients recently diagnosed with HF remains underused. ${ }^{4}$ This could be leaving a treatable disease underdiagnosed and undertreated. ${ }^{3}$

\section{Key questions}

What is already known about this subject?

- Coronary artery disease (CAD) is the aetiology of about $65 \%$ of all cases of heart failure (HF). Multislice CT (MSCT) is an alternative to invasive coronary angiography for patients with a low risk of CAD, but there is no established way of predicting this risk.

What does this study add?

- In this study, we calculate the CT-HF score, a simple clinical score designed to identify as large a population as possible with a suitable risk for MSCT.

How might this impact on clinical practice?

- We estimate that using the CT-HF score could save about $15 \%$ of the cost and $21 \%$ of the radiation of evaluating HF patients for coronary disease.

The gold standard for diagnosing CAD is invasive coronary angiography (CAG). However, this test is expensive and associated with a small risk of serious adverse outcomes. ${ }^{5}$ Multislice CT (MSCT) is a non-invasive, low-radiation and less-expensive alternative with a high sensitivity and negative predictive value, but positive tests still need confirmation with $\mathrm{CAG}^{6}{ }^{6}$ Thus, MSCT is a possible gatekeeper for the use of CAG and a Class IIb recommendation in the latest European Society of Cardiology guidelines for patients with a low-to-intermediate risk of CAD. However, there is currently no established way of reliably estimating this risk and risk profiles may be different among patients with $\mathrm{HF}^{7}$

Recently, a new coronary risk score has been developed for patients with valvular heart disease undergoing surgery. ${ }^{8}$ Our aim is to develop a similar score for patients with newly diagnosed HF. 


\section{METHODS}

All patients undergoing CAG in Denmark are registered either in the Web-PATS database (for patients from the Capital Region and the Region of Zealand) or the Western Denmark Heart Registry. We obtain data from 2010 to 2014 of patients who underwent a CAG with the primary indication of newly diagnosed HF.

These databases included the details of the procedure as well as any history of ischaemic heart disease (IHD), such as prior percutaneous coronary intervention (PCI), coronary artery bypass graft (CABG) or acute myocardial infarction (AMI). Significant CAD was defined as a stenosis $>70 \%$ ( $>50 \%$ for the left main coronary artery) or with a fractional flow reserve $<0.80$. For these analyses, we chose to exclude all patients with a history of CAD (defined as prior PCI, CABG or AMI) or chronic kidney disease (defined as an estimated glomerular filtration rate $<30 \mathrm{~mL} / \mathrm{min} / 1.73 \mathrm{~m}^{2}$ ). Additionally, known predictors of CAD were registered, including age, sex, left ventricular ejection fraction (LVEF), diabetes mellitus (DM), family history of IHD, smoking, hypertension and hyperlipidaemia.

The data from the Web-PATS registry were used to develop a risk score which was then validated on the patients registered in the Western Denmark Heart Registry. The goal was to identify as large a group of patients as possible while remaining cost-effective.

Though similar in composition, there were differences between the two databases as the Western Danish Heart Registry did not register symptoms of angina or shortness of breath (eg, New York Heart Association class), patient body mass index (BMI), history of prior stroke or extracardiac arteriopathy (intermittent claudication, aortic aneurysm or dissection, confirmed $>50 \%$ carotid stenosis, previous or planned intervention on the abdominal aorta, limb arteries or carotids). As some of these factors were generally thought to be strong predictors of $\mathrm{CAD}$, we choose to include them in the calculations of the score. Thus, all calculations on the validation cohort were made without these factors.

To estimate the expected savings of using MSCT as a gatekeeper for CAG, we reviewed the literature and national agencies and found prices for MSCT and CAG in seven countries-the USA, ${ }^{9}$ the UK, ${ }^{10}$ Germany, ${ }^{11}$ Australia, ${ }^{12}$ South Korea, ${ }^{6}$ Denmark, ${ }^{13}$ and Sweden. ${ }^{14}$ From these resources, we saw that the cost of both CAG and MSCT varies significantly between countries. CAG had a mean cost of $€ 1129$ ranging from $€ 1973$ in Australia ${ }^{12}$ to $€ 560$ in South Korea. ${ }^{6}$ For MSCT, the mean cost was $€ 396$, or about a third of the cost of a CAG, ranging from $€ 663$ in Australia to $€ 99$ in Germany. ${ }^{11}$ In all countries surveyed, the cost of a CAG was at least double the cost of an MSCT, with the highest price difference in the UK, ${ }^{10}$ where the cost of a CAG $(€ 1424)$ amounted to around six times the price of an MSCT $(€ 240)$.

To estimate radiation dosage, we used data from a recent head-to-head comparison of MSCT and CAG. ${ }^{15}$
Using these, we calculated the difference in expenses and radiation if MSCT was used as a gatekeeper for CAG compared with the routine use of CAG.

MSCT only provided anatomical information and thus, the physiological significance of a potential stenosis still needed to be re-evaluated by CAG. Based on a previous study of MSCT in patients with $\mathrm{HF}^{16}{ }^{16}$ we estimated the re-evaluation rate to be three times the number of patients with significant CAD on CAG. We divided patients into groups according to their score and calculated the cost-effectiveness of the score. This was done by calculating how much money and radiation could be saved per 100 patients in each group factoring in the cost of the initial MSCT as well as the expected number of re-evaluations. The cost-effectiveness of different cut-off values was visualised in a cumulative graph showing the combined savings of different cut-off values factoring in expected re-evaluations, the number of patients in each group and the costs of the procedures.

\section{Statistics}

Suspected risk factors of CAD collected in the Web-PATS database were tested with univariate logistic regression for an association with significant CAD. We separated the patients into four age groups from a visual reading of a receiver operating characteristics (ROC) curve of age as a factor for CAD.

All risk factors univariately associated with $\mathrm{CAD}$ were entered into a multiple logistic regression with backwards elimination. Statistically non-significant risk factors were eliminated from the regression and the risk estimates were derived from the OR of each factor rounded to the nearest integer. We further used ROC to calculate the area under the curve (AUC) as a measure of the predictive ability of the score. The Youden index was calculated to explore the cut-off with the highest combined sensitivity and specificity. We used a double-sided level of significance of $5 \%$. The calculations were performed using SPSS statistics V.22 for Windows and R V.3.5.2 using RStudio V.1.0.136. ${ }^{17}$

The subsequently developed score was then recalculated for the patients of the Western Denmark Heart Registry to determine its effectiveness. The effectiveness of the score was judged by the number of patients the score classified as low-to-intermediate risk, who on examination turned out to have significant CAD.

\section{RESULTS}

From January 2010 to December 2014, a total of 3537 and 4551 patients with newly diagnosed HF were registered in the Web-PATS and the Western Danish Heart Registry, respectively. Excluding patients with a prior history of CAD or chronic kidney disease, as well as patients with missing data, the two databases included 2171 and 2795 patients, respectively (figure 1).

Baseline characteristics of the two databases can be seen in table 1 . There was a slightly higher prevalence 


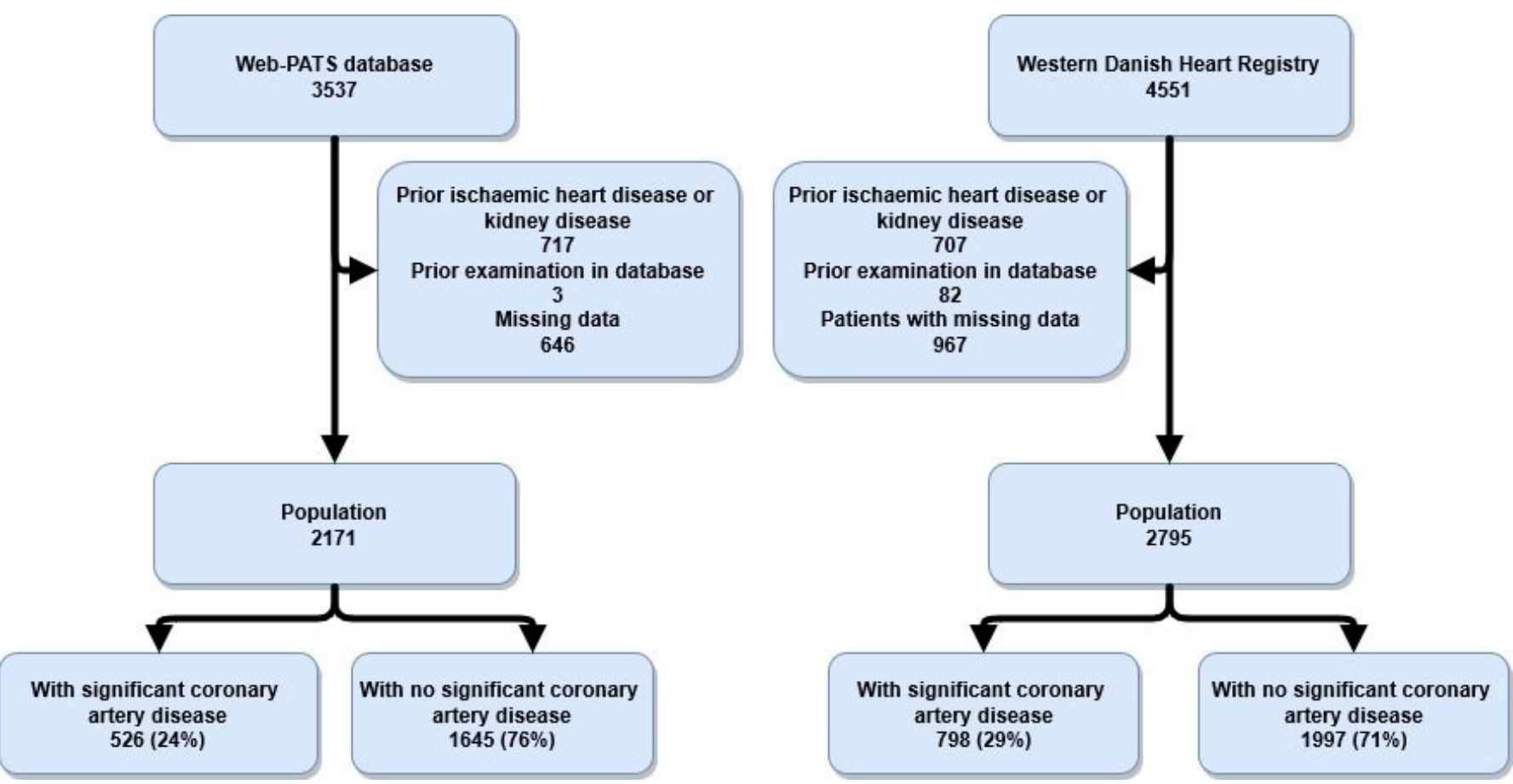

Figure 1 Consort diagram of the two databases: the original cohort (Web-PATS) and the validation cohort (the Western Denmark Heart Registry).

\begin{tabular}{|c|c|c|c|c|}
\hline Risk factors & & $\begin{array}{l}\text { Web-PATS database, } \\
n=2171\end{array}$ & $\begin{array}{l}\text { The Western Denmark } \\
\text { Heart Registry, } \\
\mathrm{n}=2795\end{array}$ & $P$ value \\
\hline Female, $n(\%)$ & & 617 (28) & $774(28)$ & 0.59 \\
\hline Hyperlipidemia, n (\%) & & $1046(48)$ & $1132(41)$ & $<0.001$ \\
\hline Hypertension, n (\%) & & $1135(52)$ & $1511(54)$ & 0.15 \\
\hline Diabetes mellitus, n (\%) & & $445(21)$ & $541(19)$ & 0.33 \\
\hline Family history of CAD, $n(\%)$ & & $523(24)$ & $813(29)$ & $<0.001$ \\
\hline Previous stroke, $\mathrm{n}(\%)$ & & $207(10)$ & NA & \\
\hline Smoking, $\mathrm{n}(\%)$ & & $1465(68)$ & $1949(70)$ & 0.09 \\
\hline Extracardial arteriopathy, n (\%) & & $133(6)$ & NA & \\
\hline $\mathrm{BMl}>30 \mathrm{~kg} / \mathrm{m}^{2}, \mathrm{n}(\%)$ & & $575(27)$ & NA & \\
\hline LVEF $<30 \%, \mathrm{n}(\%)$ & & $994(46)$ & $971(35)$ & $<0.001$ \\
\hline Angina, $n(\%)$ & & $401(19)$ & NA & \\
\hline \multirow[t]{4}{*}{ NYHA classification, n (\%) } & I & $359(17)$ & & \\
\hline & $\|$ & $993(46)$ & & \\
\hline & III & $575(27)$ & & \\
\hline & IV & $67(3)$ & NA & \\
\hline \multirow[t]{4}{*}{ Age, years, $n(\%)$} & $<51$ & $264(12)$ & $341(12)$ & \\
\hline & $51-60$ & $453(21)$ & $605(22)$ & \\
\hline & $61-70$ & $781(36)$ & $930(33)$ & \\
\hline & $>71$ & $673(31)$ & $919(33)$ & 0.23 \\
\hline
\end{tabular}

Risk factors at baseline in both databases.

Smoking defined as active or prior smoker.

BMI, body mass index; CAD, coronary artery disease; LVEF, left ventricular ejection fraction; NA, not available in the database; NYHA, New York Heart Association Functional Classification. 


\begin{tabular}{ll}
\hline Table 2 The CT-HF score & \\
\hline Risk factor & Point \\
\hline Male & 2 \\
Angina & 1 \\
Smoking & 2 \\
Hyperlipidaemia & 2 \\
\hline Diabetes mellitus & 2 \\
Extracardiac arteriopathy & 3 \\
\hline Age $51-60$ years & 2 \\
Age 61-70 years & 4 \\
Age $\geq 71$ years & 6 \\
\hline
\end{tabular}

Smoking defined as prior or active smoker. $\mathrm{HF}$, heart failure.

of hyperlipidaemia, family history of heart disease and LVEF $<30 \%$ among the patients of the Western Danish Heart Registry (all $\mathrm{p}<0.001$ ).

All inserted risk factors were significantly associated with $\mathrm{CAD}$ on the univariate logistic regressions except LVEF $<30 \%, \quad B M I>30 \mathrm{~kg} / \mathrm{m}^{2}$ and NYHA classification (online supplementary table 1). Multivariate regressions showed no significant association between CAD and family history of CAD, prior stroke or hypertension. The final score included the risk factors: sex, hyperlipidaemia, DM, smoking, extracardiac arteriopathy, angina and age (table 2). ROC was performed on the primary cohort (AUC $0.72 ; 95 \%$ CI 0.69 to 0.74 ), as well as on the validation cohort (AUC $0.67 ; 95 \%$ CI 0.65 to 0.70 ) (online supplementary figure 1 ).

Using the CT-HF score, patients receive a score of 0-18. Figure 2A,B shows the CT-HF score of the patients in our two cohorts and the number of patients who had significant CAD on their CAG. From this, different possible cut-offs values can be evaluated. Using the Youden index, the optimal cut-off was 8. Further, visual estimation suggests the ideal cut-offs be about 6-9 points. Exploration of the results of different cut-offs from 6 to 9 points calculated on the Web-PATS cohort and the Western Denmark Heart Registry can be seen in online supplementary tables 2 and 3.

To examine the cost-effectiveness of using MSCT for patients at each step of the CT-HF score, we calculate the potential savings in cost and radiation dosage per 100 patients, estimating a re-evaluation rate of three for each positive MSCT. The result is seen in online

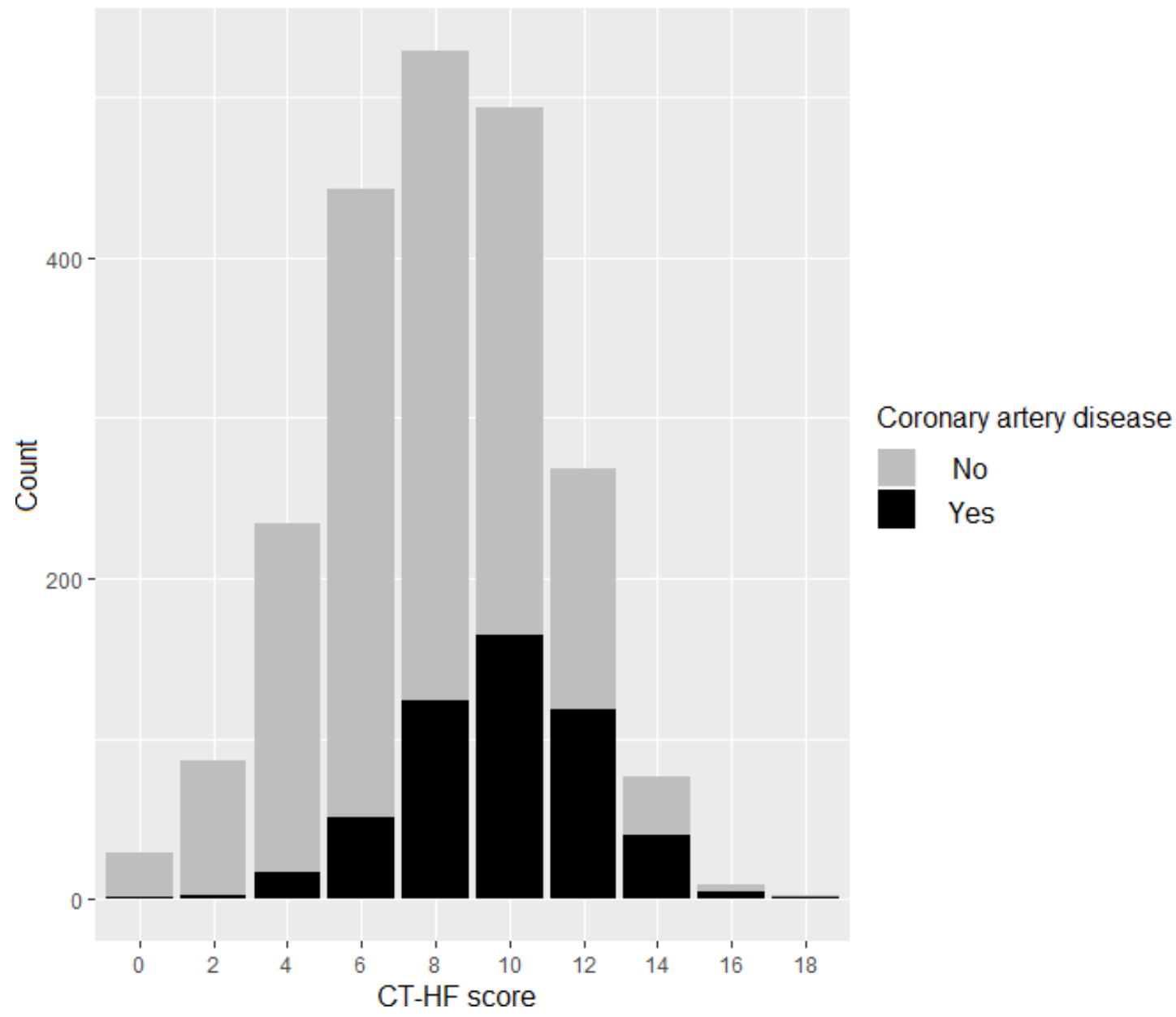

Figure 2 (A and B) CT-HF score calculated on patients in both databases and their risk of coronary artery disease. The patients are divided in to groups for each two points of the score. (A) Shows the patients of the Web-PATS database. (B) Shows the patients of the Western Denmark Heart Registry. HF, heart failure. 
A

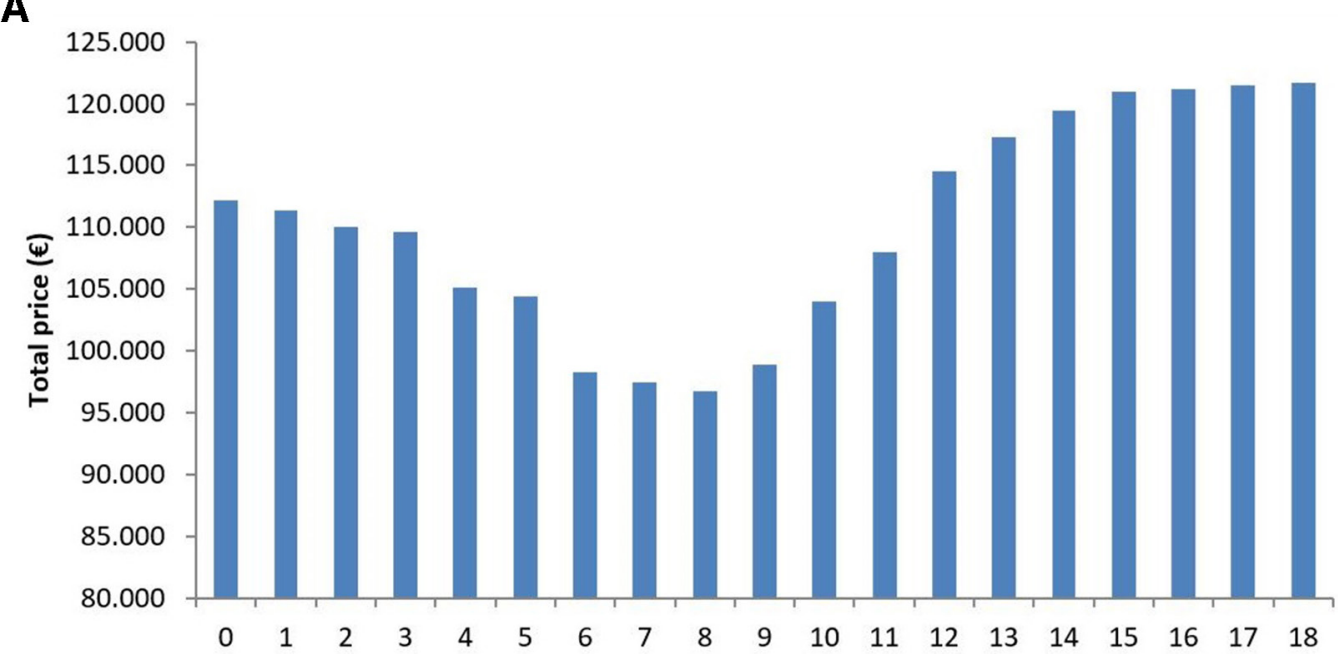

B

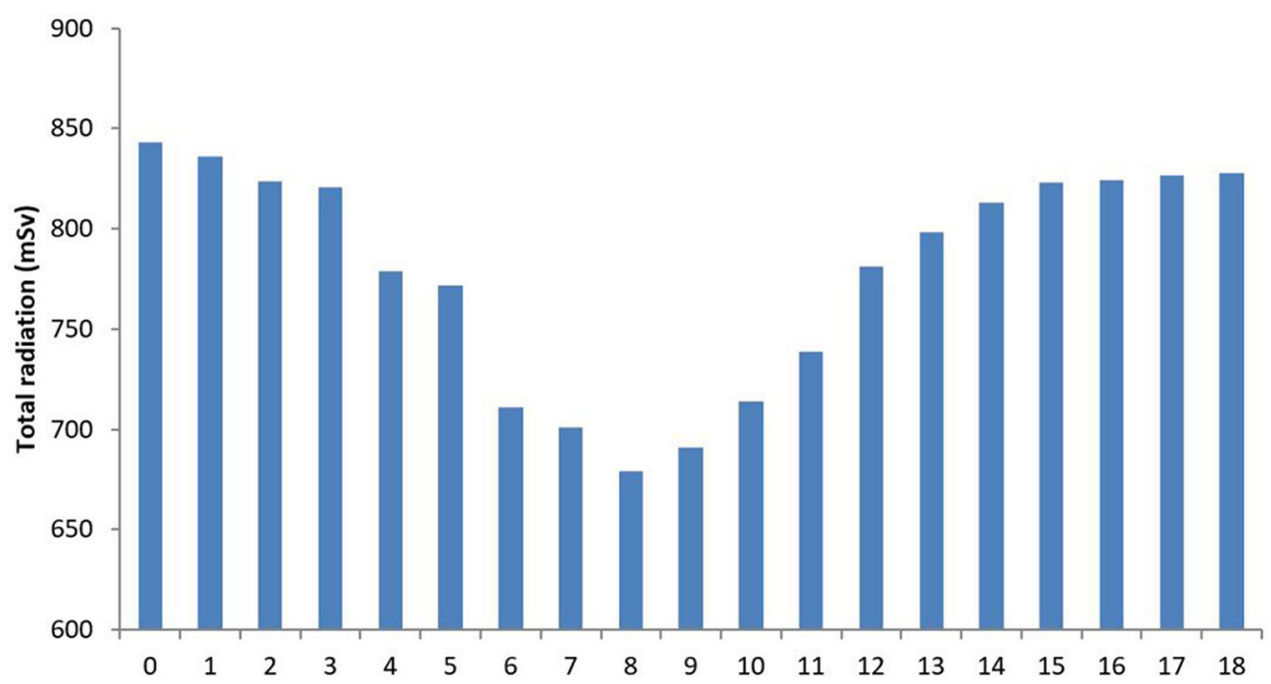

Figure 3 (A and B) A cumulative graph of price $(€)$ calculated for a mean price of $€ 1129.3$ for CAG and $€ 395.74$ for MSCT and radiation dosage (MSV) calculated for a mean dosage of $8.5 \mathrm{mSv}$ for CAG and $2.1 \mathrm{mSv}$ for MSCT. CAG, coronary angiography; MSCT, multislice CT.

supplementary figure 2A,B for expenses and radiation dosage, respectively. Further exploring ideal cut-off point for testing with MSCT, we construct a cumulative graph showing the estimated total cost, factoring in the number of expected re-evaluations for each hypothetical cut-off, shown in figure $3 \mathrm{~A}, \mathrm{~B}$.

The cost-effectiveness of different potential cut-off points varies from country to country with the difference in cost of the tests. For all countries, however, an MSCTfirst approach would be cost-effective at below 7 points, while patients with more than 9 points have too high a risk of CAD. At a mean price of $€ 1129$ for a CAG and $€ 396$ for an MSCT, the most cost-effective cut-off would be 8 points, where the savings would be about $14 \%$ of the total price. For radiation dosage, the relatively high radiation dose of a CAG (around $8 \mathrm{mSv}$ ) compared with an MSCT (around $2 \mathrm{mSv}$ ) results in an optimal cut-off at 8 points. At this cut-off, about $20 \%$ of the total radiation would be spared.

\section{DISCUSSION}

We have developed a simple clinical score based on known risk factors of $\mathrm{CAD}$ that can predict the risk of CAD in patients with newly diagnosed HF. Patients with a low score may benefit from an MSCT-first approach, potentially saving money, radiation as well as complications.

There are several limitations to our findings. First, while the two databases are similar in many respects, unfortunately, the Western Danish Heart Registry include no classification of symptoms of angina or extracardiac arteriopathy, both factors included in our score. We have chosen to include these factors in our analysis since they are both strong predictors of CAD in the Web-PATS registry. Another limitation is the possible information bias as not all patients diagnosed with HF receive CAG or, in fact, any sort of evaluation of possible CAD. Whereas the patient population in this study is already subject to a clinical judgement that they are at risk of having CAD. 
Thus, our findings might not be generalisable to all patients with HF. However, as these patients were evaluated, they probably represent a higher risk of CAD than a complete population of HF patients. Thus, if calculated on all patients, we would expect a lower average CT-HF score as well as a lower average prevalence of CAD. All patients in this study received a CAG and therefore, we do not know the true re-evaluation rate with CAG if an MSCT-first approach was implemented.

MSCT is a Class IIb recommendation in the latest European Society of Cardiology guidelines for patients with a low-to-intermediate risk of CAD. ${ }^{7}$ However, not all patients with $\mathrm{HF}$ are suitable for an MSCT-first approach. Patients with a history of CAD were excluded from this analysis. Further, we chose to exclude patients with a history of chronic kidney disease. This was done mainly because of the risk of contrast-induced nephropathy associated with the increased use of contrast in MSCT and in eventual re-evaluation. Additionally, patients with chronic kidney disease have a higher risk of coronary calcifications and were, thus, more likely to have blooming artefacts, potentially leaving the procedure inconclusive. Clinically unstable patients should be spared the possible extra waiting time of an MSCT and instead be sent directly to $\mathrm{CAG}$ where acute revascularisation is available. Also, though recent studies have shown the ability of MSCT to exclude CAD in patients with atrial fibrillation, ${ }^{18}$ this is not routinely done in all centres due to technical issues. Some of the specific clinical characteristics of HF patients may in itself limit the accuracy and reproducibility of MSCT, such as inability to hold their breath as well as difficulties controlling the heart rate. HF patients also represent a population at a higher risk of contrast-induced nephropathy, ${ }^{19}$ something to keep in mind when sending patients to an MSCT that in general uses more contrast than a CAG. This underscores the importance of patient selection as unnecessary examinations with MSCT could lead to additional cases of contrast-induced nephropathy.

The most common complications of a CAG are vascular (about $4 \%-7 \%$ of procedures). ${ }^{5}$ Most of these are minor bleedings, but some are larger or more complicated (eg, pseudoaneurysm or arteriovenous fistula) and may even result in the patient needing a transfusion and prolonging the hospital stay. More serious complications are rare, such as stroke $(0.07 \%)$, myocardial infarction $(<0.05 \%)$ and death $(<0.08 \%)$, though they may be more frequent in patients with congestive HF. ${ }^{5}$ MSCT is non-invasive, making it less expensive ${ }^{20}$ and associated with a lower mean radiation dose. ${ }^{15}$

Large systematic reviews have shown MSCT to be a highly sensitive test for the exclusion of CAD, with a sensitivity of $>98 \% .{ }^{21}{ }^{22}$ However, MSCT still only provide anatomical information and physiological significance, and obstructiveness cannot be routinely assessed from the scan. For this reason, positive findings still have to be confirmed with a conventional invasive CAG. With the addition of fractional flow reserve, MSCT accuracy may improve further limiting the number of re-evaluations with CAG needed. Though still primarily used as a test of CAD, MSCT does provide additional data among patients with HF regarding morphology (eg, hypertrophic cardiomyopathy or dilated cardiomyopathy) as well as aetiology (eg, sarcoidosis). ${ }^{23}$ Functional imaging tests, such as Rubidium-82 positron emission tomography imaging, is a possible alternative to MSCT as a gatekeeper for CAG. However, MSCT is generally viewed as the most cost-effective gatekeeper. ${ }^{24}$

An advantage of MSCT is higher availability since the procedure is more easily implemented at centres than invasive procedures. Another potential advantage is the ability to visualise and diagnose significant extracardiac pathology in surrounding structures, mostly mediastinum and lungs. The prevalence of such findings varies in the literature from about $14 \%$ up to $28 \%$. $^{25} 26$

The newly developed score, the CT-HF score, is an easily calculated clinical score that stratifies HF patients according to their risk of CAD. What constitutes low to intermediate on the score remains to be determined. A cut-off of 9 points identifies about $56 \%-64 \%$ of patients with a risk of $13 \%-21 \%$ of CAD, while a lower cut-off of 7 points yields $36 \%-38 \%$ of patients with a risk of $9 \%-14 \%$. Using the mean price of CAG and MSCT across the seven countries, a cut-off of 8 would save about $14 \%$ of the cost and $20 \%$ of the radiation. At 7 points, this drops to $14 \%$ of the cost and $18 \%$ of the radiation.

With the improved survival after AMI and improved treatment of patients with $\mathrm{HF}$, the prevalence of $\mathrm{HF}$ is only expected to rise in the coming decades. ${ }^{12} \mathrm{CAD}$ is among the most common causes of HF contributing in as many as $65 \%$ among male HF patients. ${ }^{1}$ With the publishing of the STICH trial 10-year follow-up, we now have data for patients with $\mathrm{HF}$ and CAD treated with CABG showing a robust long-term benefit. ${ }^{3}$ Further, HF patients with concomitant CAD have an indication for implantable cardioverter-defibrillator, ${ }^{27}$ which have shown a clear prognostic benefit unlike patients with non-ischaemic HF for whom the benefit seems to be limited to younger patients. ${ }^{28}$ This underscores the importance of identifying patients with $\mathrm{HF}$ and $\mathrm{CAD}$ for whom treatment is clinically relevant.

A possible alternate approach for low-risk patients could be the evaluation of coronary artery calcium (CAC) as the first step before MSCT. Though cut-offs for different levels of risk of CAD varies in the literature, a CAC of 0 is universally associated with a low risk of events ${ }^{29} 30$ even among patients with $\mathrm{HF}^{31}$ with long-term follow-up studies finding a low risk of mortality as far as 12 years ahead of a measurement. ${ }^{32}$ Thus, patients with a low CT-HF score $(<4)$ may avoid a full MSCT in the presence of a CAC of 0 .

\section{CONCLUSION}

A simple clinical risk score can identify a subgroup of patients with newly diagnosed $\mathrm{HF}$ with a low risk of CAD. These patients may benefit from an MSCT-first approach, 
reducing radiation dosage, the risk of complications as well as the price of the procedures.

Contributors The study was designed by RBH and KKI. Data collection was handled by RBH, MP-H, TE, AS, MH, FP, MS, HM, HE, RS and LK. KKI and RBH did the data analyses, LK and MS helped with data interpretation. RBH and KKI wrote the first manuscript. All the authors critically revised the manuscript and agree to be accountable for all aspects of the work.

Funding The authors have not declared a specific grant for this research from any funding agency in the public, commercial or not-for-profit sectors.

Competing interests None declared.

Patient consent for publication Not required.

Ethics approval The study complied with the Declaration of Helsinki II and was approved by the Danish Data Protection Agency (j.nr. 2014-41-3656) and the Danish Health and Medicines Authority (3-3013-1178/1), who determined no patient consent was necessary under Danish law.

Provenance and peer review Not commissioned; externally peer reviewed.

Data availability statement Data are available on reasonable request.

Open access This is an open access article distributed in accordance with the Creative Commons Attribution Non Commercial (CC BY-NC 4.0) license, which permits others to distribute, remix, adapt, build upon this work non-commercially, and license their derivative works on different terms, provided the original work is properly cited, appropriate credit is given, any changes made indicated, and the use is non-commercial. See: http://creativecommons.org/licenses/by-nc/4.0/.

ORCID iD

Rasmus Bo Hasselbalch http://orcid.org/0000-0003-4274-6268

\section{REFERENCES}

1. Gheorghiade M, Sopko G, De Luca L, et al. Navigating the crossroads of coronary artery disease and heart failure. Circulation 2006;114:1202-13.

2. Levy D, Kenchaiah S, Larson MG, et al. Long-Term trends in the incidence of and survival with heart failure. $N$ Engl $J$ Med 2002;347:1397-402.

3. Velazquez EJ, Lee $\mathrm{KL}$, Jones $\mathrm{RH}$, et al. Coronary-Artery bypass surgery in patients with ischemic cardiomyopathy. $N$ Engl $J$ Med 2016;374:1511-20.

4. Doshi D, Ben-Yehuda O, Bonafede M, et al. Underutilization of coronary artery disease testing among patients hospitalized with new-onset heart failure. J Am Coll Cardiol 2016;68:450-8.

5. Tavakol M, Ashraf S, Brener SJ. Risks and complications of coronary angiography: a comprehensive review. Glob J Health Sci 2012;4:65-93.

6. Lee S-P, Jang EJ, Kim Y-J, et al. Cost-Effectiveness of coronary CT angiography in patients with chest pain: comparison with myocardia single photon emission tomography. J Cardiovasc Comput Tomogr 2015;9:428-37.

7. Ponikowski P, Voors AA, Anker SD, et al. 2016 ESC Guidelines for the diagnosis and treatment of acute and chronic heart failure: The Task Force for the diagnosis and treatment of acute and chronic heart failure of the European Society of Cardiology (ESC)Developed with the special contribution of the Heart Failure Association (HFA) of the ESC. Eur Heart J 2016;37:2129-200.

8. Hasselbalch RB, Engstrøm T, Pries-Heje M, et al. Coronary risk stratification of patients undergoing surgery for valvular heart disease. Int J Cardiol 2017;227:37-42.

9. Budoff MJ KR, Ahmadi N, Nasserian C, et al. 64-slice computed tomographic angiography for the diagnosis of intermediate risk coronary artery disease: an evidence-based analysis. Ont Health Technol Assess Ser 2010;10:1-44.

10. Westwood M, Al M, Burgers L, et al. A systematic review and economic evaluation of new-generation computed tomography scanners for imaging in coronary artery disease and congenital heart disease: Somatom definition flash, Aquilion one, brilliance iCT and discovery CT750 HD. Health Technol Assess 2013;17:1-243.
11. Dorenkamp M, Bonaventura K, Sohns C, et al. Direct costs and costeffectiveness of dual-source computed tomography and invasive coronary angiography in patients with an intermediate pretest likelihood for coronary artery disease. Heart 2012;98:460-7.

12. Kreisz FP, Merlin T, Moss J, et al. The pre-test risk stratified cost-effectiveness of 64-slice computed tomography coronary angiography in the detection of significant obstructive coronary artery disease in patients otherwise referred to invasive coronary angiography. Heart, Lung and Circulation 2009;18:200-7.

13. Statens serum Institut. Takstsystem. In: Sektor for National Sundhedsdokumentation og Forskning, (ed), 2014. Available: https:// sundhedsdatastyrelsensundhedsdatastyrelsen.dk/da/afregning-ogfinansiering/takster-drg/takster-2014

14. utvärdering Sbfmos. Datortomografi för misstänkt kranskärlssjukdom. SBU Alert-Rapport 2011.

15. Herzog BA, Wyss CA, Husmann L, et al. First head-to-head comparison of effective radiation dose from low-dose 64-slice CT with prospective ECG-triggering versus invasive coronary angiography. Heart 2009;95:1656-61.

16. Sousa PA, Bettencourt N, Dias Ferreira N, et al. Role of cardiac multidetector computed tomography in the exclusion of ischemic etiology in heart failure patients. Rev Port Cardiol 2014;33:629-36.

17. R Core Team. R: a language and Eviroment for statistical computing 2016.

18. Sohns C, Kruse S, Vollmann D, et al. Accuracy of 64-multidetector computed tomography coronary angiography in patients with symptomatic atrial fibrillation prior to pulmonary vein isolation. Eur Heart J Cardiovasc Imaging 2012;13:263-70.

19. Rosenstock JL, Gilles E, Geller AB, et al. Impact of heart failure on the incidence of contrast-induced nephropathy in patients with chronic kidney disease. Int Urol Nephrol 2010;42:1049-54.

20. Zeb I, Abbas N, Nasir K, et al. Coronary computed tomography as a cost-effective test strategy for coronary artery disease assessment a systematic review. Atherosclerosis 2014;234:426-35.

21. Paech DC, Weston AR. A systematic review of the clinical effectiveness of 64-slice or higher computed tomography angiography as an alternative to invasive coronary angiography in the investigation of suspected coronary artery disease. BMC Cardiovasc Disord 2011;11:32.

22. Sun Z, Ng K-H. Diagnostic value of coronary CT angiography with prospective ECG-gating in the diagnosis of coronary artery disease: a systematic review and meta-analysis. Int $J$ Cardiovasc Imaging 2012;28:2109-19.

23. Butler J. The emerging role of multi-detector computed tomography in heart failure. J Card Fail 2007;13:215-26.

24. Moss AJ, Williams MC, Newby DE, et al. The updated NICE guidelines: cardiac CT as the first-line test for coronary artery disease. Curr Cardiovasc Imaging Rep 2017;10:15.

25. Bendix K, Jensen JM, Poulsen S, et al. Coronary dual source multi detector computed tomography in patients suspected of coronary artery disease: prevalence of incidental extra-cardiac findings. Eur $J$ Radiol 2011;80:109-14.

26. Larsen LH, Kofoed KF, Dalsgaard M, et al. Assessment of coronary artery disease using coronary computed tomography angiography in patients with aortic valve stenosis referred for surgical aortic valve replacement. Int J Cardiol 2013;168:126-31.

27. Moss AJ, Hall WJ, Cannom DS, et al. Improved survival with an implanted defibrillator in patients with coronary disease at high risk for ventricular arrhythmia. multicenter automatic defibrillator implantation trial Investigators. N Engl J Med 1996;335:1933-40.

28. Køber L, Thune JJ, Nielsen JC, et al. Defibrillator implantation in patients with nonischemic systolic heart failure. N Engl J Med 2016;375:1221-30.

29. Budoff MJ, Mayrhofer T, Ferencik M, et al. Prognostic value of coronary artery calcium in the promise study (prospective multicenter imaging study for evaluation of chest pain). Circulation 2017;136:1993-2005.

30. Sarwar A, Shaw LJ, Shapiro MD, et al. Diagnostic and prognostic value of absence of coronary artery calcification. JACC: Cardiovascular Imaging 2009;2:675-88.

31. Abunassar JG, Yam Y, Chen L, et al. Usefulness of the Agatston score $=0$ to exclude ischemic cardiomyopathy in patients with heart failure. Am J Cardiol 2011;107:428-32

32. Budoff MJ, Shaw LJ, Liu ST, et al. Long-term prognosis associated with coronary calcification: observations from a Registry of 25,253 patients. J Am Coll Cardiol 2007;49:1860-70. 